\title{
Effects of Liquid Bi Particles on Grain Growth of Fe-1.9vol\%Bi Alloy
}

\author{
Takehito HAGISAWA, ${ }^{1)}$ Hajime MITSUI, ${ }^{2)}$ Ikuo OHNUMA, ${ }^{1)}$ Ryosuke KAINUMA ${ }^{3)}$ and Kiyohito ISHIDA ${ }^{1)}$ \\ 1) Department of Materials Science, Graduate School of Engineering, Tohoku University, Aoba-yama 6-6-02, Sendai 980-8579 \\ Japan. $\quad$ 2) Fukushima Technology Centre, Machiike-dai 1-12, Koriyama 963-0215 Japan. \\ 3) Institute of Multidisciplinary Research for Advanced Materials (IMRAM), Tohoku University, Katahira 2-1-1, Sendai 980-8577 \\ Japan.
}

(Received on January 4, 2008; accepted on April 30, 2008)

\begin{abstract}
The recrystallization and grain growth characteristics of pre-deformed $\mathrm{Fe}-1.9 \mathrm{vol} \% \mathrm{Bi}$ alloy specimens in the two-phase region of $\alpha \mathrm{Fe}$ and liquid Bi were investigated by microstructural observation. Precipitate-free zones (PFZs) were mainly formed in the vicinity outside of the curved grain boundaries. Furthermore, large Bi particles were also observed on the grain boundaries of the matrix along the PFZs. These results suggest that the intragranular liquid Bi particles were trapped and dragged by grain boundaries. The grain growth of the matrix phase was extremely retarded by the effect of this dragging.
\end{abstract}

KEY WORDS: liquid particle; dragging effect; Ostwald ripening; interfacial energy; grain growth; diffusion.

\section{Introduction}

It is generally known that the high-wettable liquid phase in polycrystalline materials causing the formation of filmlike structure along matrix grain boundaries results in liquid metal embrittlement. However, it has recently been reported by Koike et al. ${ }^{1)}$ that Al-Bi alloys which include a small amount of liquid Bi particles show a superplasticity of more than $200 \%$. Furthermore, Kainuma et al. ${ }^{2)}$ reported that the grain growth in the Al-Bi alloys was retarded by the dragging of liquid $\mathrm{Bi}$ particles, that precipitate-free zones (PFZs) were formed in the vicinity outside of the curved grain boundaries and that larger particles grew on the grain boundaries along the PFZs. The same kind of phenomenon has been reported in several other alloy systems. For instance, Ashby and Centamore ${ }^{3)}$ observed that the dispersing liquid oxide particles in the $\mathrm{Cu}$ matrix phase moved together with the grain boundaries. They concluded that the average dragging distance is dependent on the viscosity of the particles. Koch et al. $^{4)}$ and Ziling et al. $^{5)}$ also reported a similar phenomenon on $(\mathrm{Cr}, \mathrm{Fe})_{23} \mathrm{C}_{6}$-type carbides in an austenite stainless steel and on $\mathrm{Al}_{2} \mathrm{O}_{3}$ particles in a $\mathrm{Cu}-$ $\mathrm{Al}$ alloy, respectively. On the other hand, Geguzin and Krivoglaz $^{6}$ and Gottstein and Shvindlerman ${ }^{7)}$ theoretically analyzed the dragging phenomenon as the migration of a spherical particle receiving an external force. A Monte Carlo simulation of the grain growth behavior in polycrystalline material with highly mobile particles examined by Hassold and Srolovitz ${ }^{8)}$ showed that the grain growth of the matrix phase can be retarded by the existence of mobile particles.

Practical applications of metallic alloys with a dispersed phase with a low melting point have been conducted in the field of machinable materials. For instance, $\mathrm{Pb}$ has long been used as free-cutting material not only in steels, but also in aluminum- and copper-based bearing alloys. However, it has become necessary to replace $\mathrm{Pb}$ with other material, because of environmental problems with the toxicity of $\mathrm{Pb}$. Therefore, inclusions such as manganese sulfide, graphite, and calcium oxide have been used, and the addition of $\mathrm{Bi}$ in steel is also expected to be a promising candidate of $\mathrm{Pb}$-free machinable steel, the melting point of $\mathrm{Bi}$ $(545 \mathrm{~K})$ being comparable to that of $\mathrm{Pb}$.

Figure 1 shows the Fe-Bi binary phase diagram, ${ }^{9)}$ which indicates that pure $\mathrm{Bi}$ particles are dispersed in a pure $\mathrm{Fe}$ matrix through a monotectic reaction. In the present work, the effects of liquid $\mathrm{Bi}$ particles on the recrystallization and grain growth characteristics of $\alpha \mathrm{Fe}$ in the $\mathrm{Fe}-\mathrm{Bi}$ alloy were investigated.

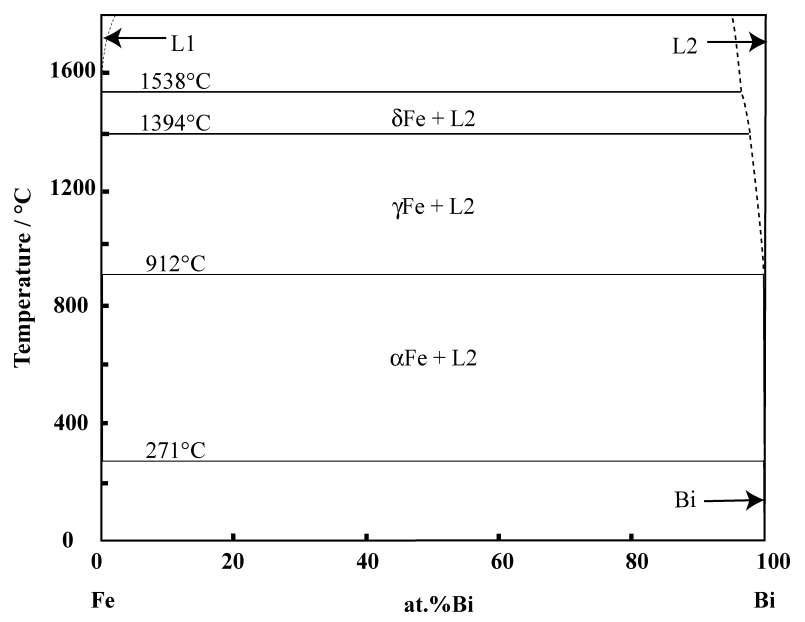

Fig. 1. Fe-Bi binary phase diagram. 


\section{Experimental Procedure}

A Fe-1.9vol\%Bi alloy and a pure Fe were prepared as columnar ingots with a diameter of $12 \mathrm{~mm} \phi$ by induction melting in an argon atmosphere. Each ingot was cold-rolled into a sheet with a thickness of $2.4 \mathrm{~mm}$ by $80 \%$ reduction. The specimens cut from the rolled sheet were isothermally annealed at $1173 \mathrm{~K}$, which is higher than the melting temperature of $545 \mathrm{~K}$ for $\mathrm{Bi}$, for recrystallization and grain growth, and then quenched in ice water. The microstructure of the annealed specimens was observed by optical microscopy (OM) and scanning electron microscopy (SEM). An etchant consisting of $50 \mathrm{vol} \%$ of ethanol and $50 \mathrm{vol} \%$ of nitric acid was used for the OM observation. The mean grain radius of the matrix phase was determined by quantitative microstructure analysis, ${ }^{10)}$ and the volume fraction and the mean radius of the liquid $\mathrm{Bi}$ particles were estimated with an image analysis software (Win Roof ${ }^{\circledR}$ ). The recrystallization was examined by the micro-Vickers hardness (MVH) test and the microstructural observation. The chemical compositions of the matrix phase and the liquid particle were determined by electron probe microanalysis (EPMA), the calibration being performed by ZAF correction of the data of more than 5 points for each phase.

\section{Results}

\subsection{Recrystallization in Fe-Bi Alloy}

Since the grain growth continuously proceeds after recrystallization during isothermal annealing at $1173 \mathrm{~K}$ after cold-rolling, the end of recrystallization was estimated by hardness measurements.

Figure 2 shows the value of MVH versus the annealing time $t$ for the pre-deformed Fe-1.9vol\%Bi alloy at $1173 \mathrm{~K}$. In the case of a pre-deformed pure Fe, the MVH, which shows $H V=185$ in the as-rolled specimen, drastically decreases to $\mathrm{HV}=95$ due to annealing for $30 \mathrm{~s}$ and maintains a $\mathrm{MHV}$ of around $\mathrm{HV}=100$ at all the annealing times over $30 \mathrm{~s}$. On the other hand, the MVH of the pre-deformed $\mathrm{Fe}-1.9 \mathrm{vol} \% \mathrm{Bi}$ alloy, which is $\mathrm{HV}=170$ in the as-rolled specimen, gradually decreases until $120 \mathrm{~s}$ and becomes steady at about $\mathrm{HV}=85$ after $120 \mathrm{~s}$.

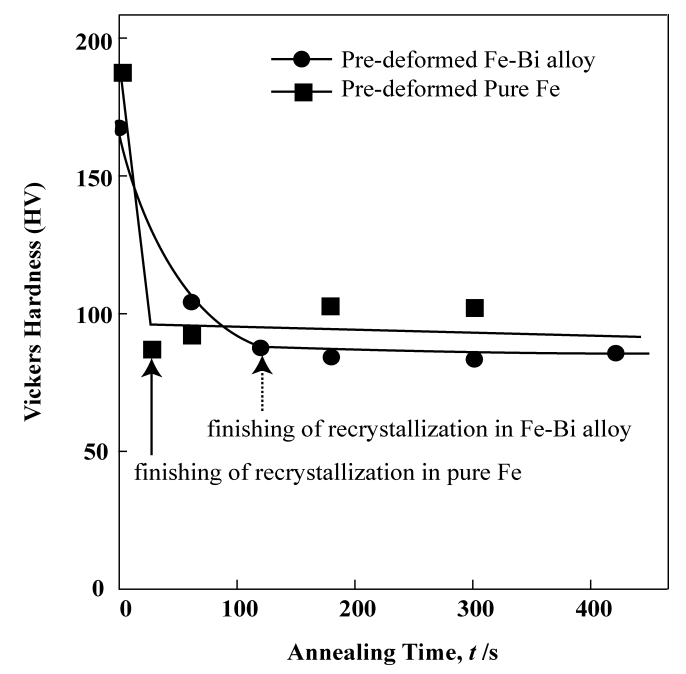

Fig. 2. Vickers hardness of pre-deformed $\mathrm{Fe}-1.9 \mathrm{vol} \% \mathrm{Bi}$ alloy annealed at $1173 \mathrm{~K}$
Figures 3(a), 3(b) and 3(c) show the OM micrographs of the as-rolled specimen and the as-annealed specimens for $60 \mathrm{~s}$ and $120 \mathrm{~s}$, respectively. While the microstructure of the as-deformed specimen shows anisotropy of the matrix grains prolonged parallel to the rolling direction, the microstructure at $120 \mathrm{~s}$ is almost completely occupied by isotropic recrystallized grains. In the case of the microstructure at $60 \mathrm{~s}$, a mixture of the deformed and recrystallized grains is confirmed. This is consistent with the result obtained from the MVH test, suggesting that the recrystallization of the $\mathrm{Fe}-1.9 \mathrm{vol} \% \mathrm{Bi}$ alloy finishes at about $120 \mathrm{~s}$. It is worthy of note that the very fine $\mathrm{Bi}$ particles observed in the as-rolled specimen of Fig. 3(a) still seem to exist in the recrystallized specimen of Fig. 3(c) with a distribution similar to that in the as-rolled specimen. This means that the dispersion of the Bi particles hardly affects the recrystallization process.

\subsection{Grain Growth in Fe-Bi Alloy}

The stability of crystal grains is known to be related to the balance of grain boundary energies at triple junctions. For example, in the case of 2-dimensional (2-D) polycrystalline materials, hexagonal grains with an equilibrium angle of $120^{\circ}$ at the boundary junction are most stable, and the total number of boundaries around a grain with more and less than six sides may grow and shrink, respectively. However, it is usually difficult to directly confirm such motion of grain boundaries. In the present study, the trajectory
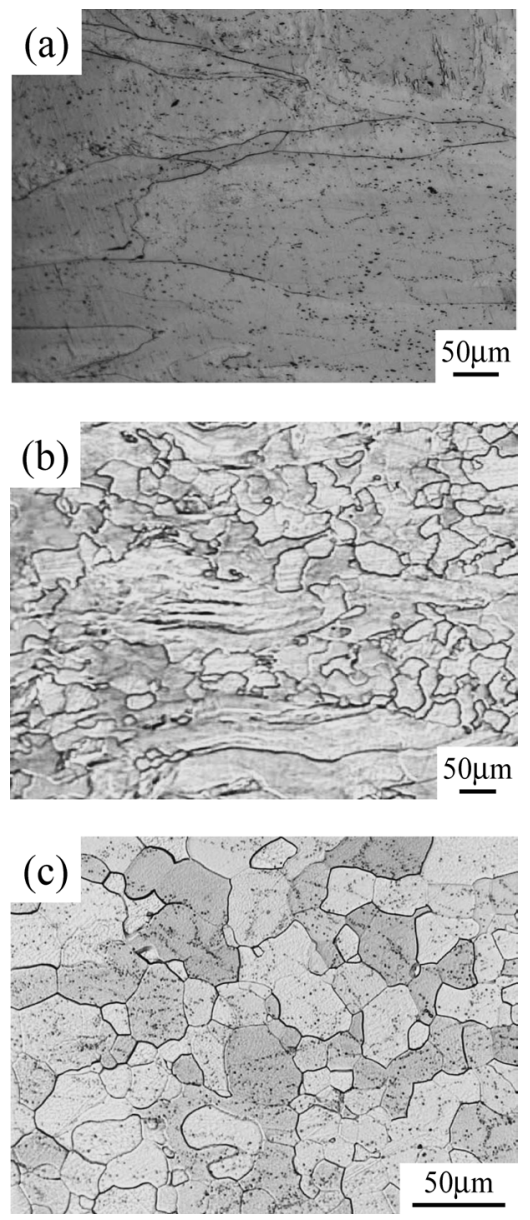

Fig. 3. Optical micrographs of $\mathrm{Fe}-1.9 \mathrm{vol} \% \mathrm{Bi}$ specimens asrolled (a), and as-annealed at $1173 \mathrm{~K}$ for $60 \mathrm{~s}$ and $120 \mathrm{~s}$ after cold-rolling (b) and (c). 
(a)

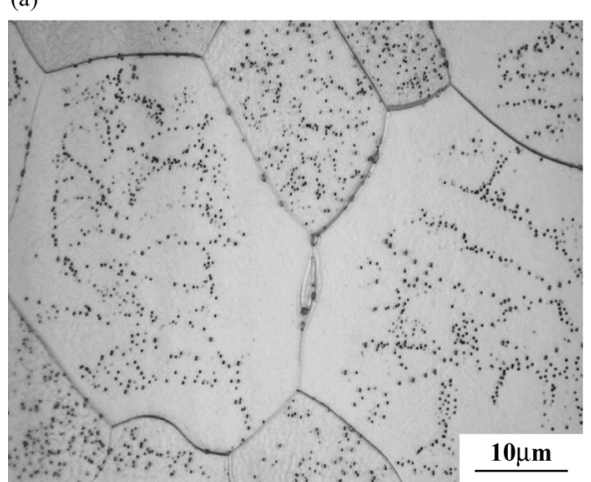

(b)

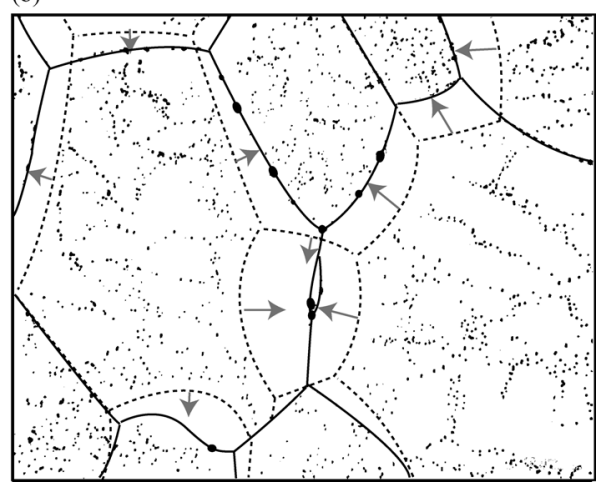

Fig. 4. Optical micrograph (a) and schematic illustration (b) of pre-deformed $\mathrm{Fe}-1.9 \mathrm{vol} \% \mathrm{Bi}$ alloy annealed at $1173 \mathrm{~K}$ for 3 weeks.

of the grain boundary migration was observed by the distribution of fine liquid particles dispersed in the matrix grain.

Figures 4(a) and 4(b) show an OM micrograph and a schematic illustration of the $\mathrm{Fe}-1.9 \mathrm{vol} \% \mathrm{Bi}$ alloy annealed at $1173 \mathrm{~K}$ for 3 weeks. The broken lines represent the previous location of the grain boundary. PFZs are observed in the vicinity outside of curvature of the grain boundaries, and some large particles are located only on the grain boundaries along the PFZs. These results imply that fine intragranular Bi particles are swept out by grain boundaries and that the swept particles preferentially grow due to Ostwald ripening on the grain boundaries.

Figure 5 shows the mean radius versus the annealing time for the intra- and inter-granular liquid $\mathrm{Bi}$ particles at $1173 \mathrm{~K}$. The ripening rate of the grain boundary particles is faster than that of intragranular ones. This suggests that the ripening mechanism of the grain boundary particles is basically different from that of the intragranular ones. The ripening mechanism of the liquid $\mathrm{Bi}$ particles will be discussed later on.

Annealing time dependence of the mean grain radius for the $\mathrm{Fe}-1.9 \mathrm{vol} \% \mathrm{Bi}$ alloy at $1173 \mathrm{~K}$ is shown together with that for the pure Fe in Fig. 6. It is apparent that the grain growth in the $\mathrm{Fe}-\mathrm{Bi}$ alloy containing the liquid Bi particles is much more sluggish than that in the pure Fe. These results show that the dragging of the liquid $\mathrm{Bi}$ particles plays an important role in the grain growth of the matrix phase.

\section{Discussion}

\subsection{Effects of Liquid Bi Particles on Recrystallization}

Second-phase particles sometimes act as pinning sites for

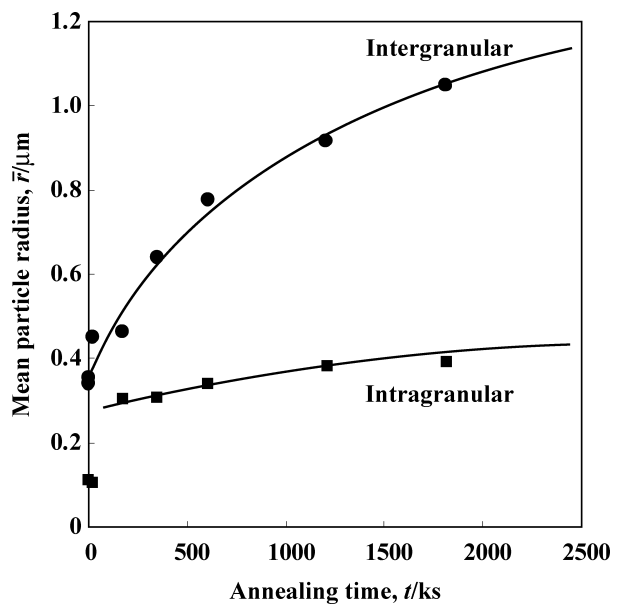

Fig. 5. Growth of liquid Bi particles at $1173 \mathrm{~K}$.

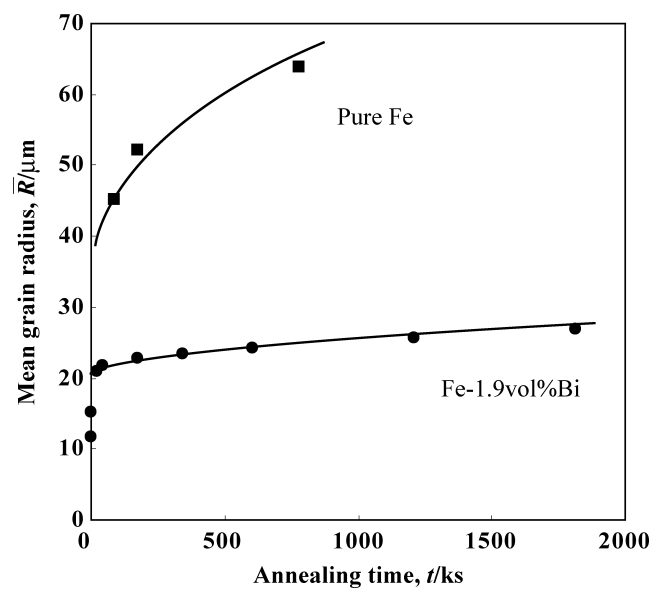

Fig. 6. The mean grain radius versus the annealing time for Fe-1.9vol\%Bi alloy at $1173 \mathrm{~K}$.

the interface migration of the recrystallizing grains. ${ }^{11)}$ When the second-phase particles are randomly distributed in the deformed matrix, the pinning force $\Delta G_{\text {pin }}$ on the unit area of grain boundaries is expressed by

$$
\Delta G_{\mathrm{pin}}=\frac{3 \cdot f \cdot \sigma}{2 \cdot r}
$$

where $f$ and $r$ are the volume fraction and the mean particle radius of dispersing particles, respectively, and $\sigma$ is the grain boundary energy of the matrix phase. For the present $\mathrm{Fe}-1.9 \mathrm{vol} \% \mathrm{Bi}$ alloy annealed at $1173 \mathrm{~K}$ for $2 \mathrm{~min}$, values of $f=0.019$ and $r=0.11 \mu \mathrm{m}$ are obtained from the experimental result. On the other hand, $\sigma=0.80 \mathrm{~J} \cdot \mathrm{m}^{-2}$ is reported as the grain boundary energy for $\alpha \mathrm{Fe} .{ }^{12)}$ Using these parameters, the pinning force is evaluated as

$$
\Delta G_{\mathrm{pin}}=2 \times 10^{5} \mathrm{~J} \cdot \mathrm{m}^{-3}=0.2 \mathrm{MPa}
$$

Since the driving force for recrystallization is usually on the order of about $1-10 \mathrm{MPa},{ }^{11)}$ the recrystallization process of the matrix is expected to be hardly affected by the liquid $\mathrm{Bi}$ particles. This result can be confirmed by the fact that the distribution of the fine liquid $\mathrm{Bi}$ particles before the recrystallization seems to be inherited by the recrystallized microstructure, as shown in Fig. 3. 


\subsection{Ostwald Ripening of Liquid Bi Particles}

\subsubsection{Intragranular Bi Particles}

It is well known that the driving force for the ripening of particles is the consumption of interfacial energy between the matrix and the particles. If the ripening of particles is controlled by volume diffusion of solute atoms in the matrix phase, the ripening rate of spherical particles is expressed by

$$
\bar{r}^{3}-\bar{r}_{0}^{3}=k_{3} \cdot t
$$

where $t$ is the annealing time, $\bar{r}$ and $\bar{r}_{0}$ are the mean particle radii at $t=t$ and $t=0$, respectively. $k_{3}$ is the rate constant given by ${ }^{13,14)}$

$$
k_{3}=\frac{8 D_{\mathrm{x}} \cdot \sigma_{\alpha \beta} \cdot N_{\mathrm{x}} \cdot V_{\beta}}{9 R T}
$$

where $D_{\mathrm{x}}$ is the impurity diffusion coefficient of the solute in the matrix phase, $\sigma_{\alpha \beta}$ is the interfacial energy between the matrix and particle phases, $N_{\mathrm{x}}$ is the solubility of the solute in the matrix phase measured in atomic fraction, $V_{\beta}$ is the molar volume of the particle, $R$ is the gas constant and $T$ is the absolute temperature. The annealing time dependence of the cube of the mean particle radius at $1173 \mathrm{~K}$ is shown in Fig. 7. As can be seen, the cube of the mean particle radius linearly increases with increasing annealing time. The experimental rate-constant for the ripening of the intragranular particles can be estimated to be $k_{3}^{\exp }=$ $2.2 \times 10^{-26} \mathrm{~m}^{3} \cdot \mathrm{s}^{-1}$ from the slope of Fig. 7 . In order to confirm the reliability of this mechanism in the present case, the theoretical rate-constant was calculated by Eq. 3 as $k_{3}^{\mathrm{cal}}=5.5 \times 10^{-26} \mathrm{~m}^{3} \cdot \mathrm{s}^{-1}$ using the parameters shown in Appendix A1. The theoretical value is on the same order as the experimental one, and it can be considered that the ripening of the intragranular particles in the $\mathrm{Fe}-\mathrm{Bi}$ alloy is controlled by the impurity volume diffusion of $\mathrm{Bi}$ in the matrix phase.

\subsubsection{Intergranular Bi Particles}

When the ripening of the intergranular $\mathrm{Bi}$ particles is controlled by grain boundary diffusion, the ripening rate is given by

$$
\bar{r}^{4}-\bar{r}_{0}^{4}=k_{4} \cdot t
$$

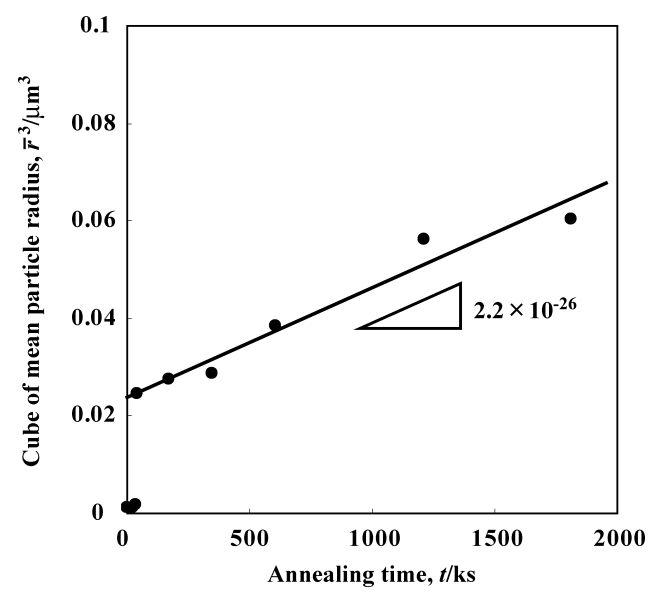

Fig. 7. The cube of the mean radius of the intragranular Bi particles versus the annealing time for $\mathrm{Fe}-1.9 \mathrm{vol} \% \mathrm{Bi}$ alloy at $1173 \mathrm{~K}$. where $k_{4}$ represents the rate constant shown by ${ }^{15)}$

$$
k_{4}=\frac{9 w \cdot D_{\mathrm{gb}} \cdot \sigma_{\alpha \beta} \cdot N_{\mathrm{x}}(\mathrm{gb}) \cdot V_{\mathrm{m}}}{32 A \cdot B \cdot R T}
$$

Here, $w$ is the grain boundary thickness, $D_{\mathrm{gb}}$ is the grain boundary diffusion coefficient and $N_{\mathrm{x}}(\mathrm{gb})$ is the concentration of the solute at the grain boundary. $A$ and $B$ are the constants written as

$$
A=\frac{2}{3}+\frac{\sigma_{\mathrm{b}}}{2 \sigma}+\frac{1}{3}\left(\frac{\sigma_{\mathrm{b}}}{2 \sigma}\right)^{3}
$$

and

$$
B=\frac{1}{2} \ln \left(\frac{1}{f_{\mathrm{b}}}\right)
$$

where $\sigma_{\mathrm{b}}$ is the grain boundary energy of the matrix phase and $f_{\mathrm{b}}$ is the fraction of the grain boundary covered by the second-phase particles. The grain boundary diffusion is usually given with the segregation coefficient $K_{\mathrm{gb}}=$ $N_{\mathrm{x}}(\mathrm{gb}) / N_{\mathrm{x}}$. Using a form of $K_{\mathrm{gb}} \cdot w \cdot D_{\mathrm{gb}}$ in the diffusion database, Eq. (5) can be rewritten as

$$
k_{4}=\frac{9 K_{\mathrm{gb}} \cdot w \cdot D_{\mathrm{gb}} \cdot \sigma_{\alpha \beta} \cdot N_{\mathrm{x}} \cdot V_{\mathrm{m}}}{32 A \cdot B \cdot R T}
$$

In order to examine the validity of Eqs. (4)-(7), the fourth power of the mean radius $\bar{r}$ of the intergranular Bi particles is plotted against the annealing time $t$ in Fig. 8(a). As shown in Fig. 8(a), it was found that the linear relationship between $\bar{r}^{4}$ and $t$ is satisfied at longer annealing times. Fig-
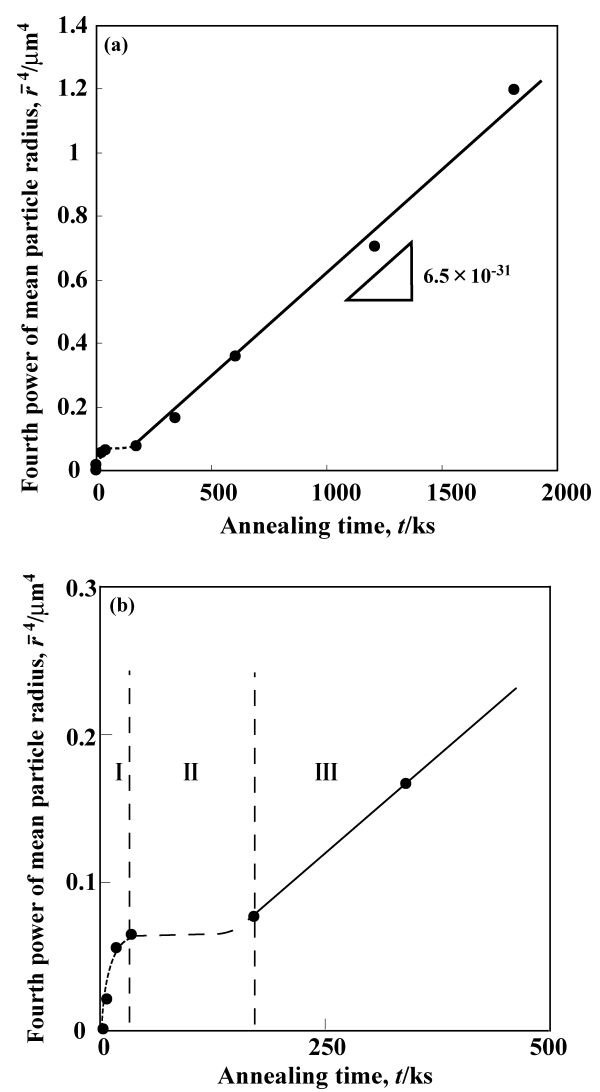

Fig. 8. (a) The fourth power of the mean radius of the intergranular $\mathrm{Bi}$ particles versus the annealing time for $\mathrm{Fe}-$ $1.9 \mathrm{vol} \% \mathrm{Bi}$ alloy at $1173 \mathrm{~K}$ and, (b) the short annealingtime corner. 
ure 8(b) shows the fourth power of the mean radius $\bar{r}$ versus the annealing time $t$ at shorter annealing times. As shown in Fig. 8(b), it was found that the ripening kinetics can be divided into three stages. In stage $\mathrm{I}$, the mean radius $\bar{r}$ rapidly increases with increasing annealing time $t$. On the other hand, the value of $\bar{r}$ remains almost constant in stage II. After that, the particle ripening of the fourth power law proceeds in stage III. These different mechanisms of ripening kinetics can be explained as follows. Figures 9(a)-(d) and 9(e) show schematic illustrations of the microstructure evolution in the $\mathrm{Fe}-\mathrm{Bi}$ alloy and the particle radius distribution (PRD) of the intergranular Bi particles, respectively. At the beginning of heat treatment after recrystallization, fine liquid Bi particles are homogeneously dispersed in the matrix grains as illustrated in Fig. 9(a). In the first stage of the grain growth and the particle ripening, the number of the intergranular particles is quite small and the grain boundary can move easily because of a weak pinning effect by the particles. Since the intragranular particles are continuously trapped by the migrating grain boundaries and immediately united with one another on the boundaries, they rapidly grow in stage I as shown in Fig. 8(b) and the distribution of the particle radius $r$ is unimodal as shown with curves $\mathrm{A}$ and B in Fig. 9(e). In stage II, the single hump splits into a bimodal distribution as shown with arrows of the curve $\mathrm{C}$ in Fig. 9(e). The newly formed, larger sized hump seems to be caused by the fourth power ripening of trapped and united particles in stage I. Simultaneously, grain boundary trapping continues to proceed, resulting in the other hump being retained at smaller sizes. However, as the migration rate of the grain boundary in stage II is slower than that in stage I, the number of trapped liquid particles is not so large, which results in the formation of small intergranular particles in addition to large particles ripened in stage I, as shown in Figs. 9(b)-(c). In consequence, evolution of the apparent particle size averaging of both large particles ripened in stage I and small particles is stagnant until the steady state is achieved as shown in stage II in Fig. 8(b). After a certain amount of the liquid phase is trapped on grain boundaries, grain growth is retarded by the Zener pinning effect due to the existence of the intergranular liquid particles. A cooperative coarsening of matrix grains and grain boundary particles in accordance with the fourth power law then proceeds under a steady state in stage III as shown in Fig. 8(b). Even in stage III, grain boundaries migrate very slowly due to trapping and dragging of the intragranular particles, which results in a small hump at a small radius in distribution curve D shown in Fig. 9(e). From a practical point of view, liquid particle evolution in stage III is of prime importance. Although the presence of trapped small particles was observed in the PRD of the sample annealed for $1209.6 \mathrm{ks}$ (Stage III in Fig. 8(b)), its contribution is expected to be smaller because of the slower migration rate of the grain boundary. Therefore, the rate constant of the ripening of the intergranular particles only in stage III was quantitatively examined in the present work. The value was experimentally estimated to be $k_{4}^{\exp }=6.5 \times 10^{-31} \mathrm{~m}^{4} \cdot \mathrm{s}^{-1}$ from the slope of Fig. 8, which is compared with the theoretical rate constant calculated from Eqs. (5)-(7) as $k_{4}^{\mathrm{cal}}=3.2 \times 10^{-31} \mathrm{~m}^{4} \cdot \mathrm{s}^{-1}$ using the parameters described in Appendix A2. The calculated rate constant $k_{4}^{\text {cal }}$ is of the
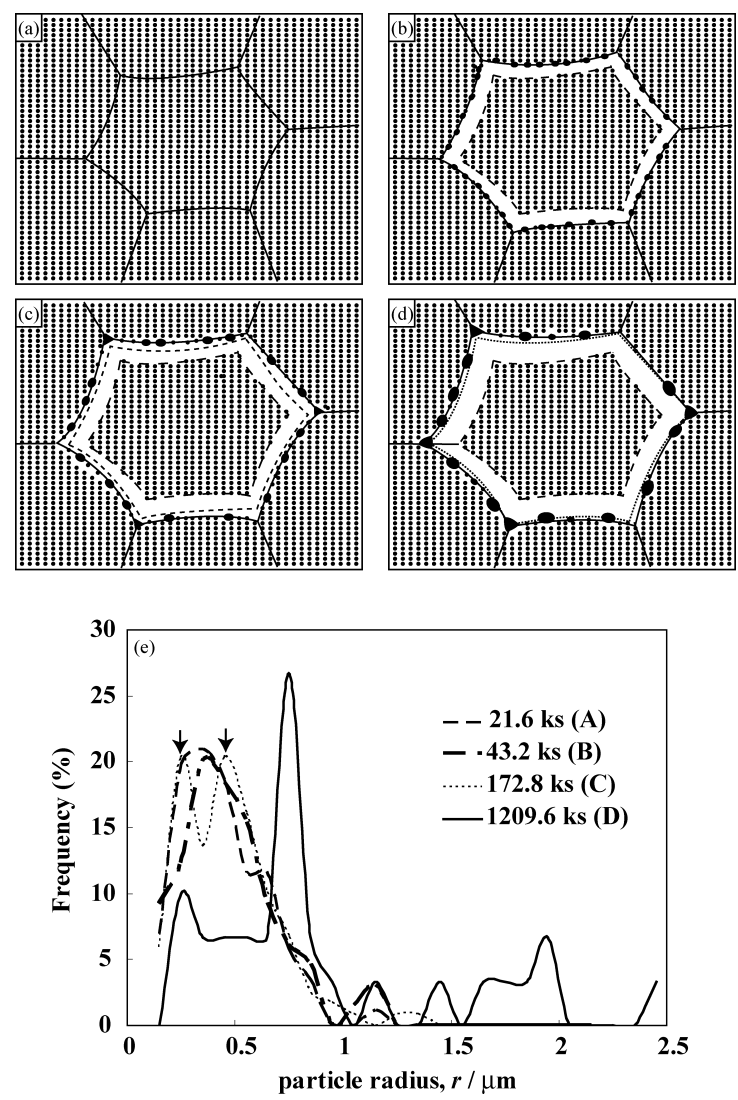

Fig. 9. (a)-(d) Schematic illustrations of grain growth in $\mathrm{Fe}-\mathrm{Bi}$ alloy and (e) the particle radius distribution of the intergranular particles in $\mathrm{Fe}-1.9 \mathrm{vol} \% \mathrm{Bi}$ alloy at $1173 \mathrm{~K}$.

same order as that of the observed $k_{4}^{\exp }$. Therefore, it can be considered that the ripening of the intergranular Bi particles at longer annealing times is basically controlled by grain boundary diffusion of the solute.

\subsection{Growth Rate of the Matrix Phase in Fe-Bi Alloy}

Interaction between the grain growth of the matrix and the second-phase particles is generally expressed by ${ }^{16)}$

$$
\bar{R}=\beta \cdot \frac{\bar{r}}{f^{m}}
$$

Here, $\bar{R}$ is the mean grain radius of the matrix, and $\bar{r}$ and $f$ are the mean radius and the volume fraction of the secondphase particle, respectively. $\beta$ and $m$ are the constants, these values of $\beta$ and $m$ having been proposed by many researchers. ${ }^{17,18)}$ In the case of the original Zener relation, ${ }^{16}$ ) the distribution of particles is assumed to be random and the correlation is given by $\beta=4 / 3$ and $m=1$. If all the particles are located on grain boundaries, the constants are theoretically given by $\beta=2$ and $m=1 / 2$. Also, 2-D simulation of this case was conducted by Doherty et al., ${ }^{19)}$ who reported that the constants are given by $\beta=1.7$ and $m=1 / 2$. In the $\mathrm{Fe}-\mathrm{Bi}$ alloy annealed for long times, the grain growth of the matrix was extremely retarded by the dispersion of the liquid $\mathrm{Bi}$ particles. This means that the ripening of the intergranular Bi particles is important as a retardation mechanism of grain boundary migration. The relationship between the matrix and the intergranular particles is therefore plotted in Fig. 10. In this figure, the abscissa represents the division of the mean radius $\bar{r}_{\mathrm{gb}}$ of the intergranular particles 


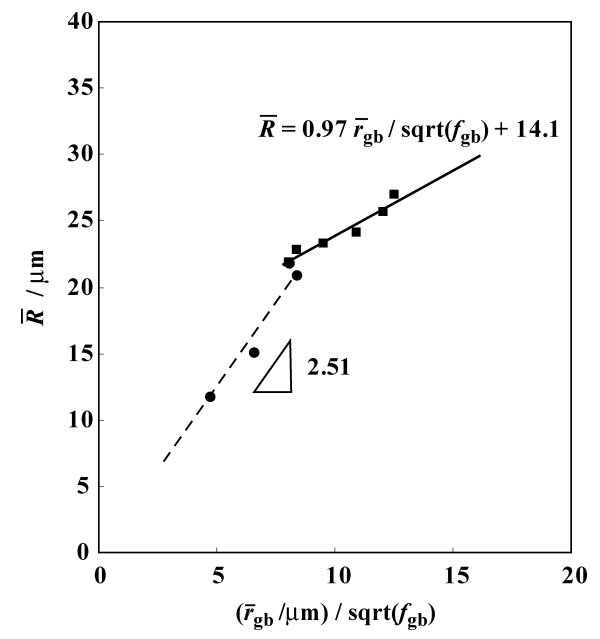

Fig. 10. Zener relation of $\mathrm{Fe}-1.9 \mathrm{vol} \% \mathrm{Bi}$ alloy at $1173 \mathrm{~K}$.

by the square root of the volume fraction of the intergranular particles. As shown in Fig. 10, the gradient of the Zener relation was divided into two regions of unsteady and steady state. This result was consistent with the experimental data for the ripening of the intergranular particles shown in Fig. 8.

If the ripening rate for the intergranular particles and the Zener relation are estimated as $\bar{r}^{4}-\bar{r}_{0}^{4}=k_{4} \cdot t$ and $\bar{R}=\beta \cdot \bar{r} / f^{\mathrm{m}}$, respectively, the grain growth rate of the matrix is evaluated by

$$
\bar{R}^{4}-\bar{R}_{0}^{4}=k_{4 \text { Matrix }} \cdot t=\left(\frac{\beta}{f^{m}}\right)^{4} \cdot k_{4} \cdot t
$$

where $k_{4 \text { Matrix }}$ is the rate constant for the grain growth. However, it was found that the Zener relation in the steady state for $\mathrm{Fe}-1.9 \mathrm{vol} \% \mathrm{Bi}$ alloy is expressed by

$$
\bar{R}=\beta \cdot \frac{\bar{r}}{f^{m}}+C
$$

Thus, the grain growth rate of the matrix can be written as

$$
(\bar{R}-C)^{4}-\left(\bar{R}_{0}-C\right)^{4}=k_{4 \text { Matrix }} \cdot t=\left(\frac{\beta}{f^{m}}\right)^{4} \cdot k_{4} \cdot t .
$$

Figure 11 shows the fourth power of $(\bar{R}-C)$ versus the annealing time $t$, where only experimental values on the steady state at long annealing times are used. $C=14.1$ was taken from the intercept of Fig. 9. From the slope of Fig. 11 , the experimental rate constant of the grain growth was estimated to be $k_{4 \text { Matrix }}^{\exp }=1.3 \times 10^{-26} \mathrm{~m}^{4} \cdot \mathrm{s}^{-1}$. In order to confirm the reliability of this mechanism in the present case, the theoretical rate constant was calculated by Eq. (11) as $k_{4 \text { Matrix }}^{\text {cal }}=1.4 \times 10^{-26} \mathrm{~m}^{4} \cdot \mathrm{s}^{-1}$, where the numerical data for calculation was used from the experimental data of the $\mathrm{Fe}-1.9 \mathrm{vol} \% \mathrm{Bi}$ alloy annealed at $1173 \mathrm{~K}$ for $4 \mathrm{~d}$. The theoretical rate constant is in good agreement with the experimental one, $k_{4 \text { Matrix }}^{\text {exp }}$. Therefore, it can be considered that the grain growth of the matrix is basically controlled by the ripening of the intergranular Bi particles.

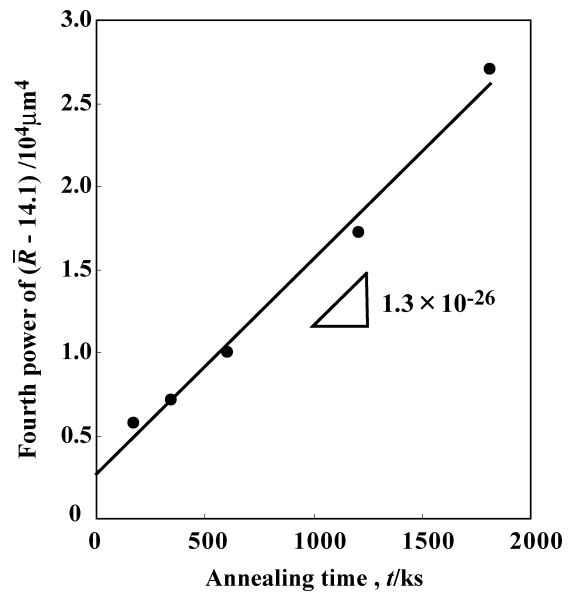

Fig. 11. The fourth power of $(\bar{R}-C)$ versus the annealing time $t$ for $\mathrm{Fe}-1.9 \mathrm{vol} \% \mathrm{Bi}$ alloy at $1173 \mathrm{~K}$.

\section{Conclusions}

The effects of the liquid Bi particles on the recrystallization and the grain growth of the matrix in the $\mathrm{Fe}-$ $1.9 \mathrm{vol} \% \mathrm{Bi}$ alloy was experimentally observed at $1173 \mathrm{~K}$. The following results were obtained in the experiment.

(1) Complete recrystallization of the Fe-Bi alloy was observed at $120 \mathrm{~s}$.

(2) Dragging of the liquid Bi particles induced by grain boundary migration was observed in the grain growth.

(3) The grain growth of the Fe-Bi alloy was extremely restricted by the dragging of the liquid Bi particles.

(4) The ripening of the intragranular particles in the $\mathrm{Fe}-\mathrm{Bi}$ alloy at was controlled by volume diffusion of $\mathrm{Bi}$ atoms in the matrix phase.

(5) The ripening of the intergranular particles in the $\mathrm{Fe}-\mathrm{Bi}$ alloy was controlled by grain boundary diffusion of Bi atoms.

(6) The grain growth of the matrix was controlled by the ripening of the intergranular particles.

\section{Acknowledgements}

Support from CREST, Japan Science and Technology Agency is acknowledged. One of the authors (I.O.) acknowledges support from the Iron and Steel Institute of Japan.

\section{REFERENCES}

1) J. Koike, K. Miki, H. Takahashi and K. Maruyama: Mater. Sci. Eng. $A$, $\mathbf{A 2 8 5}$ (2000), 158.

2) R. Kainuma, I. Ohnuma and K. Ishida: Mater. Trans, 44 (2003), 1768 .

3) M. F. Ashby and R. M. A. Centamore: Acta Metall., 16 (1968), 1081.

4) E. F. Coch and K. T. Aust: Acta Metall., 15 (1967), 405.

5) K. K. Ziling and A. I. Grankin: Izv. Vyssh. Usheb. Zaved., Fizika, 11 (1968), 157.

6) Ya. E. Geguzin and M. A. Krivoglaz: Migration of Macroscopic Inclusions in Solids, Consultants Bureau, New York, (1973).

7) G. Gottstein and L. S. Shivindlerman: Acta Metall. Mater, 41 (1993), 3267.

8) G. N. Hassold and D. J. Srolovitz: Scr. Metall. Mater, 32 (1995), 1541.

9) Binary Phase Diagrams, Vol. 1, 2nd ed., ed. by T. B. Massalski et al., ASM Int., Materials Park, OH, (1990), 736.

10) T. Sakuma and T. Nishizawa: Bull. Jpn. Inst. Met., 10 (1971), 279. 
11) F. J. Humphreys and M. Hatherly: Recrystallization and Related Annealing Phenomena, Pergamon, Oxford, (1995), 271.

12) E. D. Hondros: Interfaces Conference, ed. by R. C. Gifkins, Butterworth, London, (1969), 77.

13) I. M. Lifshitz and V. V. Slyozov: J. Phys. Chem. Solids, 19 (1961), 35.

14) C. Wagner: Elektrochem, 65 (1961), 581

15) H. P. K. Kirchner: Metall. Mater. Trans., 2 (1971), 2861.

16) C. Zener, quoted by C. S. Smith: Trans. Met. Soc. AIME., 175 (1948), 15.

17) P. A. Manohar, M. Ferry and T. Chandra: ISIJ Int., 38 (1998), 913.

18) T. Nishizawa, I. Ohnuma and K. Ishida: Mater. Trans., 8 (1997), 950.

19) R. D. Doherty, D. J. Srolovitz, A. D. Rollet and M. P. Anderson: Scr. Metall., 21 (1987), 675.

20) D. Treheux, D. Marchive, J. Delagrange and P. Guiraldenq: C. $R$. Acad. Sci., C274 (1972), 1260.

21) Smithells Metals Reference Book, 7th ed., ed. by E. A. Brandes and G. B. Brook, Butterworth, London, (1992), 14.

22) V. T. Borisov, V. M. Golikov and G. V. Shcherbedinsky: Phys. Met. Metallogr., 17 (1964), 80.

\section{Appendix A.}

\section{A1. Numerical Data for Calculation of Intragranular Particles}

Since there is no report on the impurity diffusion coefficient of $\mathrm{Bi}$ in $\alpha \mathrm{Fe}$, the diffusion coefficient of $\mathrm{Sn}$ in $\alpha \mathrm{Fe}$, $D_{\mathrm{x}}=D_{\mathrm{Sn} \text { in } \alpha \mathrm{Fe}}=3.2 \times 10^{-14} \mathrm{~m}^{2} \cdot \mathrm{s}^{-1},{ }^{20)}$ was used instead of the $D_{\mathrm{Bi} i n} \alpha \mathrm{Fe} \cdot \sigma^{\mathrm{Fe} / \mathrm{Bi}}\left(=0.63 \mathrm{~J} \cdot \mathrm{m}^{-2}\right)$ was determined by experimental measurement of the dihedral angle $\theta$ for some $\mathrm{Bi}$ particles on the grain boundaries using the relation $\sigma^{\mathrm{Fe} / \mathrm{Fe}}=2 \sigma^{\mathrm{Fe} / \mathrm{Bi}} \cdot \cos \theta . N_{\mathrm{x}}\left(=1.3 \times 10^{-3}\right)$ was determined by EPMA and $V_{\beta}=2.3 \times 10^{-5} \mathrm{~m}^{3} \cdot \mathrm{mol}^{-1}$ was estimated from the molar volume of pure $\mathrm{Bi}$ at $1173 \mathrm{~K}^{21)}$

\section{A2. Numerical Data for Calculation of Intergranular Particles}

Since no data on the grain boundary diffusion coefficient of $\mathrm{Bi}$ in the $\alpha \mathrm{Fe} D_{\mathrm{gb}}=D_{\mathrm{gb}, \mathrm{Bi} \text { in } \alpha \mathrm{Fe}}$ has been reported, the grain boundary diffusion coefficient of $\mathrm{Sn}$ in the $\alpha \mathrm{Fe}$ grain boundary, $K_{\mathrm{gb}} w D_{\mathrm{gb}, \text { Sn in } \alpha \mathrm{Fe}}=3.9 \times 10^{-19} \mathrm{~m}^{2} \cdot \mathrm{s}^{-122)}$ was used instead of $K_{\mathrm{gb}} w D_{\mathrm{gb}, \mathrm{Bi} i n} \alpha \mathrm{Fe}$. The $A$ value was on the order of 1.387 and $B=0.477$ was estimated from the experimental data of Fe-1.9vol\%Bi alloy annealed at $1173 \mathrm{~K}$ for $4 \mathrm{~d}$. 